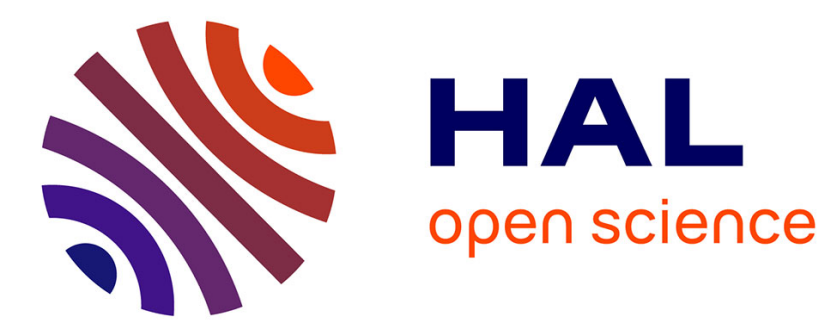

\title{
Etude des modes de survie de l'agent causal de la bactériose vasculaire du manioc, Xanthomonas campestris pathovar manihotis
}

\author{
Jean-François Daniel, Bernard Boher, P. N’Dongo, L. Makoundou
}

\section{To cite this version:}

Jean-François Daniel, Bernard Boher, P. N'Dongo, L. Makoundou. Etude des modes de survie de l'agent causal de la bactériose vasculaire du manioc, Xanthomonas campestris pathovar manihotis. Agronomie, 1985, 5 (4), pp.339-346. hal-00884767

\section{HAL Id: hal-00884767 https://hal.science/hal-00884767}

Submitted on 1 Jan 1985

HAL is a multi-disciplinary open access archive for the deposit and dissemination of scientific research documents, whether they are published or not. The documents may come from teaching and research institutions in France or abroad, or from public or private research centers.
L'archive ouverte pluridisciplinaire HAL, est destinée au dépôt et à la diffusion de documents scientifiques de niveau recherche, publiés ou non, émanant des établissements d'enseignement et de recherche français ou étrangers, des laboratoires publics ou privés. 


\title{
Etude des modes de survie de l'agent causal de la bactériose vasculaire du manioc, Xanthomo- nas campestris pathovar manihotis
}

\author{
Jean-François DANIEL \& Bernard BOHER \\ Avec la collaboration technique de P. N'DONGO \& L. MAKOUNDOU \\ Laboratoire de Phytopathologie, Centre ORSTOM de Brazzaville, Rép. Pop. du Congo
}

RÉSUMÉ

\begin{abstract}
L'analyse des mécanismes pouvant assurer le maintien de l'agent causal de la bactériose vasculaire du manioc (Manihot esculenta Crantz), permet d'expliquer le caractère endémique de cette maladie dans de nombreuses zones de culture ainsi que l'apparition d'épidémies dans des régions indemnes. Parmi ces mécanismes, deux sont essentiels : la capacité du pathogène d'avoir une phase épiphyte et celle de se conserver dans les tissus de l'hôte. Les débris végétaux, le sol, les plantes adventices ne semblent pas être des sites privilégiés pour la conservation de la bactérie. Le rôle des insectes reste à préciser mais ne doit pas être négligé.
\end{abstract}

Mots clés additionnels : Survie épiphyte, insectes, semence, distribution dans la plante.

Some aspects of survival of Xanthomonas campestris pv. manihotis, the causal agent of cassava bacterial blight.

Analysis of the mechanisms ensuring persistence of the causal agent of cassava bacterial blight explains the fact that this disease is endemic in numerous regions and causes sudden outbreaks in healthy zones. Two mechanisms are essential : the capacity of the pathogen to have an epiphytic phase and its conservation in host tissues. Debris, soil and weeds are not of major importance for the survival of the pathogen, but the role of insects should not be neglected.

Additional key words : Epiphytic survival, insect, seed, distribution in the plant.

\section{INTRODUCTION}

La bactériose vasculaire du manioc (Manihot esculenta Crantz), provoquée par Xanthomonas campestris pv. manihotis, est une maladie grave qui sévit dans toutes les zones de production de cette importante culture vivrière (Afrique, Amérique du Sud, Asie). La symptomatologie, la distribution et l'incidence de l'affection ont été particulièrement étudiées mais en ce qui concerne la survie du parasite peu de résultats sont disponibles (IKOTUN, 1976 ; PERSLEY, 1978).

Le fait que la maladie, apparemment absente dans une région, s'y développe sous une forme explosive par une brusque apparition de symptômes pose le problème de l'origine et de la conservation de l'inoculum primaire. Cet article fait le point de deux années de recherches $(1981,1982)$ sur la survie de $X$. c. pv. manihotis en République Populaire du Congo plus précisément dans la région du Pool où la maladie est endémique.

\section{MATÉRIEL ET MÉTHODES}

\section{A. Protocoles d'analyses}

Les analyses visant à l'étude des modes de survie de la bactérie sont hebdomadaires et utilisent, pour la recherche de la contamination externe, la technique de lavage par agitation $\left(3 \mathrm{~h}\right.$ à $\left.4{ }^{\circ} \mathrm{C}\right)$ dans de l'eau distillée stérile additionnée de Tween $80(1$ p. 1000$)$. La taille de l'échantillon analysé et le volume de l'eau nécessaire au lavage sont déterminés comme suit :

- Feuilles : 20 feuilles d'âge identique prélevées sur 10 plants pris au hasard et lavées dans $500 \mathrm{ml}$.

- Fleurs femelles : 100 fleurs dans $100 \mathrm{ml}$.

- Fruits : 50 fruits verts dans $500 \mathrm{ml}$.

- Graines : 100 graines dans $100 \mathrm{ml}$. 
En ce qui concerne la contamination interne des semences, 100 graines sont désinfectées superficiellement avec une solution de chlorure de mercure à 1 p. 100 pendant $15 \mathrm{mn}$, puis rincées 3 fois avec de l'eau distillée stérile. La dernière eau de rinçage est utilisée comme contrôle pour la désinfection. Les graines sont ensuite broyées dans $200 \mathrm{ml}$ d'eau distillée stérile. Ce broyat est utilisé pour la détection du pathogène sur milieu nutritif. Le taux de contamination interne étant parfois faible, pour augmenter le seuil de détection, le broyat est clarifié par centrifugation $(1500 \mathrm{~g}, 10 \mathrm{mn})$. Le surnageant est précipité à l'acétone (50 p. 100) puis centrifugé (15000 g, $20 \mathrm{mn})$. Le culot ainsi obtenu est suspendu dans $5 \mathrm{ml}$ d'eau distillée stérile et filtré sur millipore noir non fluorescent (HABG, pore de $0,45 \mu \mathrm{m}$ ). Le filtre est ensuite traité selon la technique d'immunofluorescence indirecte.

- Débris végétaux : des échantillons de $10 \mathrm{~g}$ de débris végétaux (feuilles et pétioles) récoltés au hasard à la surface du sol de la plantation sont broyés dans $100 \mathrm{ml}$ d'eau distillée stérile. Ce broyat est utilisé pour la recherche de $X$. c. pv. manihotis.

- Sol : $50 \mathrm{~g}$ de sol exempt de débris végétaux sont prélevés au niveau de l'horizon superficiel (sur une épaisseur de $10 \mathrm{~cm}$ ) et homogénéisés dans $500 \mathrm{ml}$ d'eau distillée stérile. Les échantillons sont ensuite traités selon la technique de BOLHOOL \& SCHMIDT (1970).

- Insectes : les insectes sont lavés individuellement dans $30 \mathrm{ml}$ d'eau distillée stérile (contamination externe) puis disséqués afin d'extraire le tractus intestinal. Ce dernier est dilacéré dans de l'eau pour la recherche du parasite. Pour certains lots d'insectes le tractus intestinal est fixé pour être inclus à la paraffine, coupé sériellement et fixé sur lames (PuRvis et al., 1966). Les lames, traitées selon la méthode d'immunofluorescence indirecte sont observées sous lumière ultraviolette.

- Analyse topographique de la présence de $X$. $c$. pv. manihotis dans les tiges : des plants entiers présentant les symptômes de la maladie sont découpés en fragments de $10 \mathrm{~cm}$ de long. Chaque fragment est tranché longitudinalement en 4 morceaux qui sont mis dans $50 \mathrm{ml}$ d'eau distillée stérile à $4{ }^{\circ} \mathrm{C}$ pendant $24 \mathrm{~h}$. L'eau est ensuite analysée pour la présence de la bactérie. Sa localisation dans les tissus est faite après inclusion des échantillons dans la praffine par coupes sérielles au microtome, fixation des coupes sur lames et traitement de ces dernières par la technique d'immunofluorescence (HOCKENHULL, 1978).

\section{B. Méthodes de détection}

La détection du $X$. c. pv. manihotis à partir des eaux de lavage ou des broyats est réalisée selon 2 méthodes :

1) Dilutions sérielles de la suspension initiale et étalement sur boîtes de milieu L.P.G.A. (extrait de levure $5 \mathrm{~g}$, bacto-peptone $5 \mathrm{~g}$, glucose $5 \mathrm{~g}$, agar $15 \mathrm{~g}$, actidione $50 \mathrm{mg}$, eau distillée $1000 \mathrm{ml}, \mathrm{pH} \mathrm{7,2).}$

La lecture des boîtes et le comptage s'effectuent après $72 \mathrm{~h}$ d'incubation à $30^{\circ} \mathrm{C}$.
2) Dépôt et fixation sur lames de microscope de parties aliquotes $(0,05 \mathrm{ml})$ de la suspension initiale et de la dilution $10^{-1}$. Dans le cas des suspensions de sol et de broyats de graines (recherche de la contamination interne), des aliquots de 2 et $5 \mathrm{ml}$ sont passés sur filtres Millipore noirs non fluorescents (HABG, pores de $0,45 \mu \mathrm{m})$. Les filtres sont ensuite traités selon la technique de BOLHOOL \& SCHMIDT (1973); sur les lames et les filtres on pratique l'immunofluorescence (FAURE et al., 1977), en utilisant un antisérum de lapin obtenu après injections intraveineuses de bactéries tuées par la chaleur selon le protocole d'immunisation décrit par BOLHOOL \& SCHMIDT (1973), et un sérum de mouton anti IgG de lapin (Institut Pasteur Production).

La spécificité de notre sérum a été testée sur 50 souches bactériennes provenant du sol, du tractus intestinal d'insectes et des tissus de manioc - une seule souche a réagi positivement mais sa morphologie et sa taille permettent de la différencier facilement de $X$. $c$. pv. manihotis.

L'observation se fait en épifluorescence (Leitz orthoplan, lampe HBO Osram, Ploemopak excitation BP 450-490, arrêt LP 515).

\section{RÉSULTATS}

\section{A. Survie comme épiphyte}

\section{Sur les organes aériens du manioc}

Les résultats des analyses de la microflore épiphyte du manioc menées pendant 4 années successives (DANIEL et al., 1978 ; DANIEL \& BOHER, 1978 ; DANIEL \& BOHER, 1985) montrent que, dans les plantations présentant ou ayant présenté les symptômes de la maladie, $X . c$. pv. manihotis est détecté au sein de la microflore du phylloplan du manioc. Son absence dans les plantations saines indique que cette bactérie n'est pas un composant normal de la microflore du manioc. L'agent pathogène possède la capacité d'avoir une phase épiphyte (LEBEN, 1965) au cours de son cycle, laquelle doit être relayée par une phase parasitaire.

L'étude de la dynamique des populations épiphytes montre que le taux de $X$. c. pv. manihotis en saison des pluies reste à un niveau élevé malgré d'importantes variations (fig. 1-1). En saison sèche (mai-août) on assiste à une baisse générale des populations épiphytes, qui se traduit pour le pathogène par un faible niveau de population $\left(10^{3}-10^{4}\right.$ germes par organe) avec parfois une disparition temporaire (fig. 1-1). Ces interruptions dans la détection du pathogène, compte tenu de leur caractère momentané, pourraient être expliquées par le seuil de détection de nos méthodes $\left(10^{2}-10^{3}\right.$ germes par la méthode de comptage sur boîtes, $10^{3}-10^{4}$ germes par la technique d'immunofluorescence indirecte). Pendant la période de transition (saison sèche-saison des pluies) avant l'apparition des premiers symptômes, on note une augmentation des populations de $X$.c. pv. manihotis jusqu'à atteindre des niveaux similaires à ceux détectés en saison des pluies. 
Si on établit la relation entre la dynamique des populations et le cycle phénologique de la maladie, on constate que la population de $X$. c. pv. manihotis est maximale en saison des pluies, période où s'exprime la maladie et où se fait la dissémination. Cette période correspond, pour le parasite, à une phase de multiplication épiphyte (constitution de l'inoculum nécessaire au déclenchement de l'infection) et à une phase parasitaire avec induction des symptômes et colonisation de la plante. En saison sèche, période caractérisée par un arrêt de l'expression de la maladie, la population régresse pour atteindre et se maintenir à un niveau de $10^{3}$ à $10^{4}$ germes par organe, c'est ce que nous appellons la phase de survie épiphyte. Pendant la période de transition saison sèche-saison des pluies, le pathogène entre dans une phase de multiplication épiphyte. Cette phase permet la reconstitution au niveau de l'appareil aérien de l'inoculum primaire nécessaire à l'apparition des nouveaux symptômes (fin octobredébut novembre).

La présence de la bactérie peut être mise en évidence au niveau des jeunes inflorescences, des fleurs femelles et des fruits (fig. 1-2, 1-3, 1-5). L'analyse des populations en fonction des saisons montre qu'on retrouve le pathogène en saison sèche uniquement sur les feuilles et les fruits. Ces organes semblent donc constituer les sites privilégiés pour sa survie épiphyte.

D'autre part, il est important de noter que la capacité de la bactérie d'avoir une phase épiphyte se retrouve aussi bien chez les cultivars sensibles que tolérants.

\section{Sur les organes aériens d'autres plantes}

Dans les plantations de manioc affectées par la maladie, nous avons recensé la présence de $X$. c. pv. manihotis au sein de la microflore épiphyte d'une plante cultivée (Manihot glaziovii Mueller von Argau), sur laquelle la bactérie possède aussi une phase parasitaire et de quelques plantes adventices: Celosia trigyna L. (Amaranthacées), Eupatorium odoratum L. (Composées), Fimbristylis hispidula (Vahl.) Kunth. (Cypéracées), Mariscus sumatrensis (Retz) Raynal (Cypéracées), Phyllanthus amarus Schum. \& Tonn. (Euphorbiacées) et Hymenocardia acida Tul. (Euphorbiacées).

Le caractère épisodique des analyses faites sur ces plantes ne nous permet pas de préjuger de leur rôle dans la survie du parasite en saison sèche. Cependant d'après les travaux d'ELANGO (1981) en Colombie, certaines Amaranthacées et Composées pourraient, en saison sèche, jouer le rôle de plante réservoir et favoriser, en saison des pluies, la contamination des plants de manioc qui sont dans leur voisinage.

\section{B. Survie dans les tissus de la plante-hôte}

L'utilisation de la technique classique d'isolement sur milieu nutritif et de la détection par la méthode d'immunofluorescence indirecte permet de démontrer la présence du parasite dans les tissus de l'hôte non seulement pendant la phase parasitaire dynamique (saison des pluies) mais aussi pendant la phase d'arrêt de l'expression de la maladie (saison sèche).

Tout au long de la saison sèche les résultats à l'isolement montrent que la bactérie se conserve dans le système vasculaire de la tige, dans les coussinets pétiolaires, au niveau des chancres et dans les tissus morts des rameaux desséchés. L'analyse par fragments des tiges de pieds entiers de manioc permet, d'une part, de constater que, pendant la saison sèche, la bactérie est présente d'une manière discontinue mais à tous les niveaux des tiges aériennes et même dans les tiges souterraines et les tubercules et que, d'autre part, dans un plant partiellement contaminé, les parties apparemment saines peuvent héberger la bactérie (fig. 2). Dans les tiges, l'étude fine en immunofluorescence de la localisation du parasite dans les tissus macroscopiquement sains montre que la bactérie est présente dans les gros éléments réticulés du xylème sous forme d'agrégats de corps bactériens noyés dans un mucus légèrement fluorescent. Dans les régions de la tige où l'on observe un brunissement, $X . c$. pv. manihotis est détecté dans des poches de lyse qui s'étendent aux autres tissus du bois, au parenchyme cortical et même à la moëlle.

La conservation d'une population endophyte importante permet d'expliquer la contamination des rejets qui apparaissent au démarrage de la végétation un peu avant les premières pluies. On distingue en effet, à la fin du mois d'août, sur certains rejets, des microlésions, d'où exsude un mucus bactérien qui, disséminé par l'eau de pluie et les insectes, contribue à l'augmentation du niveau des populations épiphytes du parasite. La présence de l'agent pathogène dans les tissus de l'hôte permet par ailleurs la dispersion de la maladie par le transport et l'utilisation de boutures contaminées ; il en est de même pour sa présence dans la graine qui fait l'objet du paragraphe suivant.

\section{Survie dans la semence}

Des populations importantes du parasite sont présentes, pendant toute la saison des pluies sur les fruits (fig. 1-5) et les graines (fig. 1-6) du cultivar étudié «Maloenda ». La contamination interne de la semence par des populations viables et pathogènes est démontrée, après désinfection de surface et élimination du tégument externe, par l'isolement de la bactérie à partir du broyat des tissus (fig. 1-7). L'emploi de la technique de concentration des broyats de graines décrite plus haut, couplée avec la détection par immunofluorescence, a prouvé que la graine était contaminée intérieurement pendant une grande partie du cycle de la plante (fig. 1-7, I.F. détection).

L'observation de coupes sérielles de graines contaminées naturellement, traitées selon la méthode de l'immunofluorescence indirecte, indique que $X$. c. pv. manihotis est présent dans la plupart des tissus (embryon, endosperme, téguments et caroncule) avec une fréquence plus grande au niveau de la caroncule et dans les téguments internes richement vascularisés.

\section{Survie dans les débris végétaux et dans le sol}

Chez le manioc, plante pérenne, la chute des feuilles est un phénomène constant. Une fois au sol, elles peuvent se conserver pendant plusieurs mois. La recherche du parasite dans ces débris permet de mettre en 

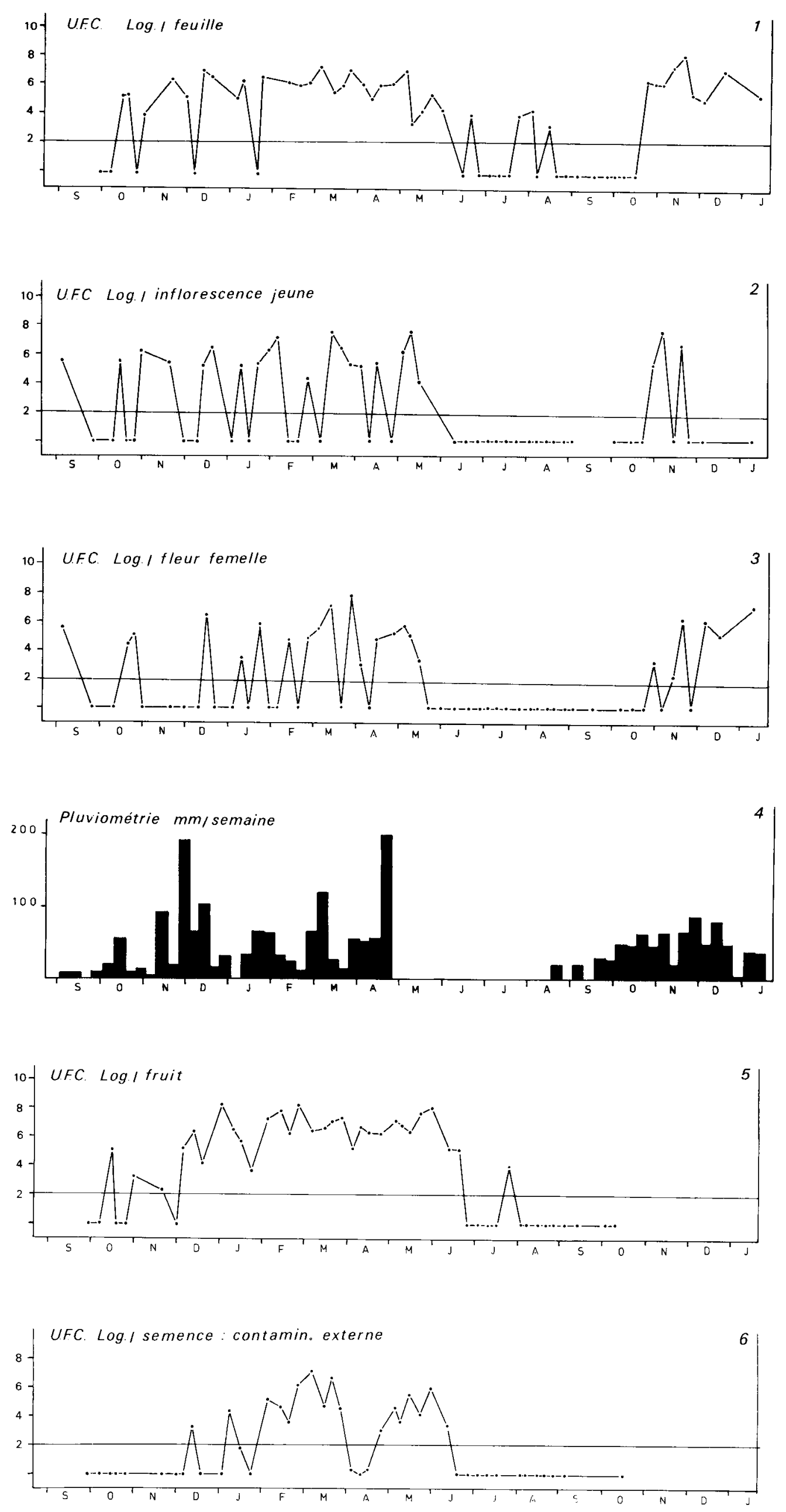

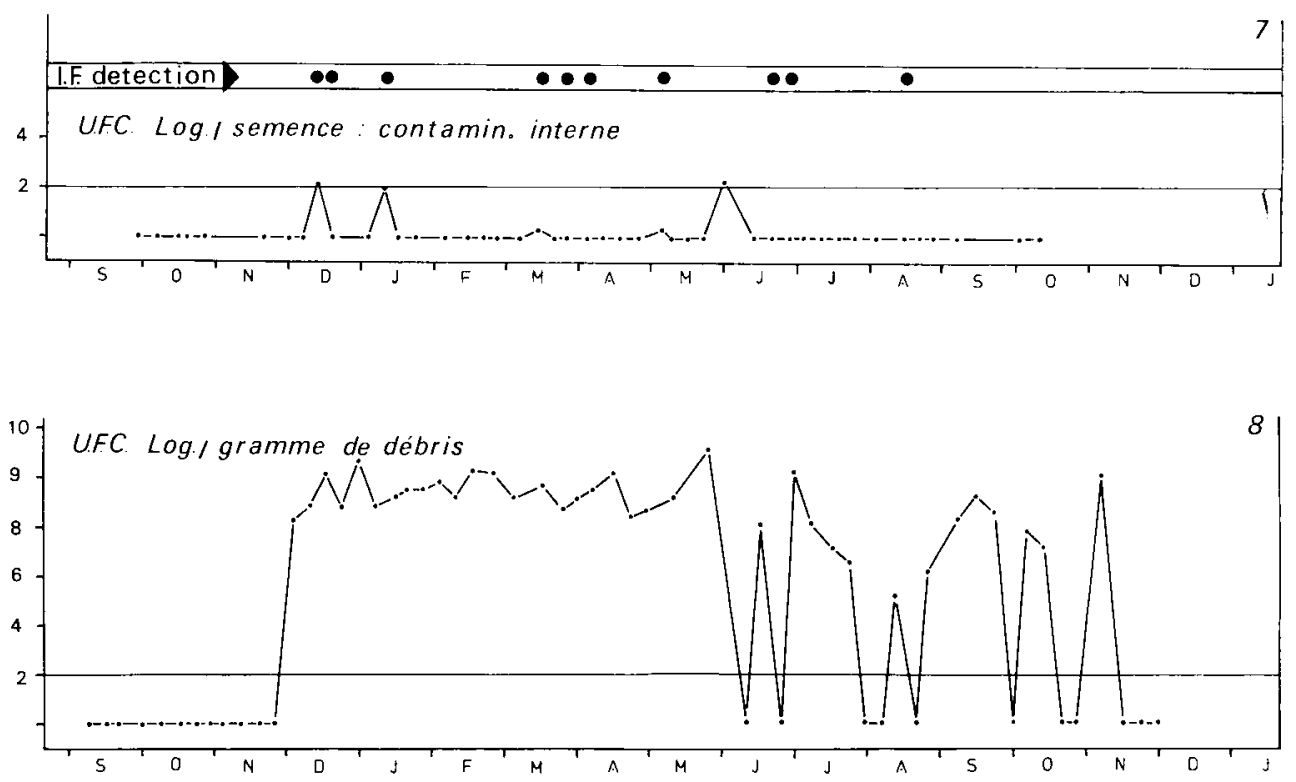

Figure 1

Resultats des analyses hebdomadaires (septembre 1981 à juillet 1982) des niveaux de populations de Xanthomonas campestris $p v$. manihotis :

- a la surface des organes aériens du manioc, feuille (courbe 1) jeune inflorescence (courbe 2). Fleur femelle (courbe 3), fruit (courbe 5) et semence (courbe 6).

- dans la semence (courbe 7),

- dans les débris végétaux tombés à terre (courbe 8).

Les niveaux de population sont donnés en logarithmes du nombre d'unités formant des colonies (U.F.C.) isolées sur milieu nutritif à partir d'un organe.

Pour la courbe 7 les points au-dessus de la courbe indiquent les analyses positives obtenues après emploi de la technique de concentration et application de la réaction d'immunofluorescence indirecte.

évidence un taux de contamination élevé pendant toute la saison des pluies et le début de la saison sèche (fig. 1-8). Ensuite, quand la saison sèche est installée, il décroît sensiblement avec de fréquentes disparitions du parasite. Le seuil de détection sur milieu LPGA, pouvant être relativement élevé $\left(10^{4}\right.$ germes $/ g$ de débris), car fonction de l'abondance de la microflore annexe, pourrait expliquer ces absences. Les analyses par immunoflorescence confortent cette hypothèse par leurs résultats positifs lorsque la détection sur LPGA est impossible à cause du niveau de la microflore d'accompagnement.

Les observations faites pendant 3 années et dans plusieurs champs indiquent que la conservation de $X$. c. pv. manihotis dans les débris pendant la saison sèche ne s'effectue pas toujours sous la forme d'une population élevée, comme la figure 1-8 le montre. La conservation du pathogène dans les débris est fonction du taux de contamination des feuilles qui sont tombées et aussi de la présence plus ou moins tardive des symptômes foliaires en fin de saison des pluies. Ces 2 facteurs dépendent essentiellement de la localisation géographique de la plantation, du cultivar et des conditions climatiques.

Au laboratoire, des échantillons de débris fortement contaminés maintenus à la température de $25^{\circ} \mathrm{C}$ et à
Le trait horizontal sur chaque graphique indique le seuil approximatif de la méthode.

La courbe 4 donne les quantités de pluies hebdomadaires.

Results of weekly analysis of population levels of X. c. pv. manihotis (September 1981 to July 1982).

- on the surface of aerial organs of cassava, leaf (curve 1), young inflorescence (curve 2), female flower (curve 3), fruit (curve 5) and seed (curve 6),

- in seed (curve 7),

- in plant debris at the soil surface (curve 8).

Population levels are given as the logarithm of colony-forming units (C.F.U.) isolated on nutrient medium.

Curve 7: - positive detection of $\mathrm{X}$. c. pv. manihotis with the indirect immunofluorescence method after concentration of samples. Horizontal line indicates on each curve the approximative threshold of the method.

Curve 4 : weekly rainfall data.

70 p. 100 d'humidité peuvent héberger le parasite pendant au moins un an, la bactérie gardant son pouvoir pathogène.

Dans les sols exempts de débris végétaux, l'application de la technique de BOLHOOL \& SCHMIDT (1970) ne permet pas de détecter l'agent pathogène à l'exception de populations résiduelles. $X . c$. pv. manihotis semble n'avoir qu'une phase transitoire dans le sol, ce qui le range dans le groupe I de la classification de BUDDENHAGEN (1965).

\section{E. Survie dans les insectes}

Les analyses de lots d'insectes provenant de l'entomofaune du manioc tout au long de son cycle cultural nous ont permis de recenser 6 espèces parmi lesquelles on peut mettre en évidence la présence externe et interne de $X$. c. pv. manihotis. Parmi ces insectes, 4 sont du type broyeur : Chrysolagria cuprina Thomson, Gonocephalum simplex Fab., Ischnothrachelus sp. Thomson, Zonocerus variegatus L. et 2 du type piqueur : Pseudotheraptus devastans Distant et un hétéroptère non encore identifié (tabl. 1).

Les bactéries présentes sur ou dans les insectes sont viables et gardent leur pouvoir pathogène. Dans le cas 
TABLEAU 1

Résultats des analyses de l'eau de lavage et de la suspension de broyage obtenues à partir d'insectes capturés dans des champs de manioc situés dans les regions de Odziba et de Brazzaville.

I.F. : Analyse par la technique d'immunofluorescence indirecte.

ISLMT: Analyse par isolement sur milieu L.P.G.A.

Results of water-wash and grinding suspension analysis of insects collected in plantations near Odziba and Brazzaville.

I.F. : analysis with the indirect immunofluorescence technique.

ISLN : Analysis with isolations on Y.P.D.A.

\begin{tabular}{|c|c|c|c|c|c|}
\hline \multirow{3}{*}{ Insectes } & \multirow{3}{*}{$\begin{array}{l}\text { Nbre total } \\
\text { d'insectes } \\
\text { analysés }\end{array}$} & \multicolumn{4}{|c|}{$\begin{array}{c}\text { Nombre d'insectes } \\
\text { portant le } X . c . \text { pv. manihotis }\end{array}$} \\
\hline & & Lavage & $\begin{array}{l}\text { Broyage } \\
\text { après désinfection } \\
\text { de surface }\end{array}$ & & \\
\hline & & IF & ISLMT & IF & ISLMT \\
\hline Chrysolagria cuprina Thomson & 105 & 11 & 1 & 41 & 23 \\
\hline Gonocephalum simplex rab. & 12 & 0 & 0 & 7 & 4 \\
\hline Ischnotrachelus sp. Thomson & 297 & 21 & 5 & 137 & 54 \\
\hline Zonocerus vartegatus Lin. & 100 & 7 & 5 & 63 & 28 \\
\hline Hétéroptère indéterminé & 77 & - & - & 29 & 8 \\
\hline Pseudotheraptus devastans Distant & 72 & 0 & 0 & 4 & 2 \\
\hline
\end{tabular}

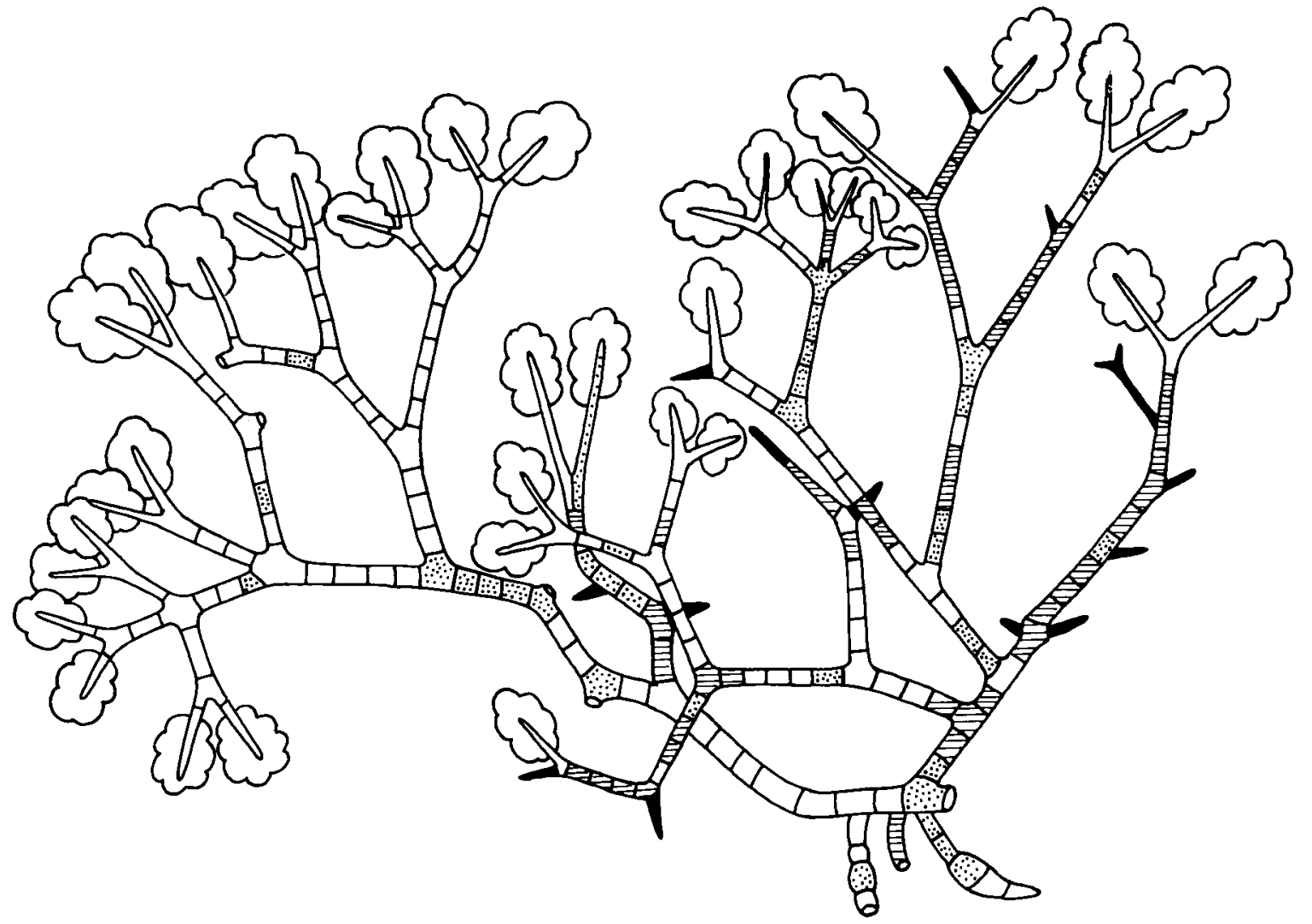

Figure 2

ZZZ Forte contamination par X. c. pv. manihotis. High populations of $\mathrm{X}$. c. pv. manihotis.

Résultat de l'analyse par fragments de $10 \mathrm{~cm}$ d'un plant de manioc de la variété "N'Ganfouo " récolté en saison sèche. Application de la méthode d'immunofluorescence indirecte.

Results of analysis of $10 \mathrm{~cm}$ fragments from cassava plant (variety «N'Ganfouo ») harvested in dry season. Application of the indirect immunofluorescence method.

$\because \because$ Faible contamination par X. c. pv. manihotis. Low populations of X. c. pv. manihotis.

Absence de contamination. Absence.

Extrémités desséchées sous l'action de X. c. pv. manihotis. Tip die-back caused with by X. c. pv. manihotis. 
du criquet, Zonocerus variegatus, le parasite suit le transit complet dans le tractus intestinal et se retrouve dans les fécès. La récolte de fécès de $Z$. variegatus dans des plantations contaminées montre que l'agent pathogène est souvent présent dans les déjections de l'insecte. Des essais préliminaires sur la conservation de $X . c$. pv. manihotis dans les fécès nous donnent une survie de 2 mois environ dans les conditions du

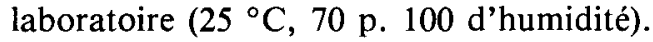

$C^{\prime}$ 'est en saison des pluies, période où s'effectue la dissémination, que l'on recense le plus grand nombre d'insectes porteurs. Au cœur de la saison sèche, période où l'on n'observe pas de lésions foliaires en cours d'évolution, le parasite a été détecté chez le criquet $Z$. variegatus. Ce résultat suggère que $X$. c. pv. manihotis pourrait survivre et même se multiplier dans le tractus intestinal de cet insecte, lequel assurerait indirectement la conservation d'un inoculum potentiel.

\section{CONCLUSION}

Les résultats des études sur les modes de survie de l'agent causal de la bactériose vasculaire du manioc, $X$. c. pv. manihotis, démontrent que cette bactérie dispose de plusieurs mécanismes qui assurent son maintien dans les plantations et expliquent le caractère endémique de la maladie dans de nombreuses zones de culture. Deux de ces mécanismes jouent un rôle prépondérant au cours du cycle de la maladie. Le premier concerne la capacité du parasite de se maintenir en tant qu'épiphyte au niveau du phylloplan. Le deuxième est lié à la conservation de la bactérie dans les tissus de la plante.

En saison sèche, période caractérisée par l'arrêt de l'expression des symptômes, l'agent pathogène survit en épiphyte au niveau du phylloplan (en particulier au niveau des feuilles) et dans les tissus de la plante. Pendant la période de transition saison sèche-saison des pluies (fin août-septembre) les populations de parasite en phase épiphyte se multiplient et produisent un inoculum important avant l'apparition des symptômes (fin octobre-début novembre). D'autre part, avec la reprise de la végétation (généralement fin août), les populations de parasite présentes dans les tissus induisent des lésions sur les tiges des jeunes repousses et le grand nombre de germes contenus dans les bactérioglées produites au niveau de ces lésions favorise la contamination des jeunes organes. Cette contamination associée à la multiplication épiphyte participe à l'installation de l'inoculum nécessaire à la réapparition des symptômes.

Les causes de la réactivation des populations endophytes au moment du redémarrage de la végétation sont encore inconnues. Il est important de noter que, compte tenu du mode de multiplication du manioc (par voie végétative), la conservation du parasite dans les tissus de l'hôte et sa réactivation au moment du redémarrage de la végétation peuvent expliquer l'apparition de la maladie dans les nouvelles plantations et, en particulier, dans les zones indemnes par introduction de boutures contaminées.
La recherche du parasite dans des plants entiers, et notamment dans les tiges destinées à la production de boutures, montre que la bactérie se distribue dans toute la plante et ce de manière discontinue. Aussi une méthode de tri sanitaire des boutures basée sur l'aspect macroscopiquement sain ou par des analyses au laboratoire (isolements, détection par immunofluorescence) ne sont pas fiables. La production de matériel sain ne peut être réalisée qu'en utilisant la culture in vitro (méristèmes, micro-boutures) après contrôles bactériologiques.

Le rôle des débris végétaux du sol, dans le maintien de la maladie d'un cycle cultural à l'autre, paraît, par contre, beaucoup moins important.

Les débris végétaux jonchant le sol pendant toute la saison sèche peuvent permettre la survie de populations importantes mais uniquement dans des plantations fortement contaminées. Les conditions de faible humidité sont favorables à la survie du parasite dans les débris végétaux de manioc et, par contre, la conservation est mauvaise dans les conditions de forte humidité. C'est une des raisons invoquées par PERSLEY (1978) pour expliquer l'absence de bactériose vasculaire dans les régions forestières.

La présence et la conservation de la bactérie dans la semence impose, bien que la graine soit peu utilisée par l'agriculteur, que des mesures soient prises pour éviter les échanges de semences et que l'emploi de la technique de culture in vitro soit généralisée pour l'échange de matériel végétal.

Le problème posé par la contamination de la graine n'est pas encore résolu. La forte population de $X . c$. pv manihotis à la surface du fruit et la présence de la bactérie dans les tissus de celui-ci suggèrent une pénétration au cours de la maturation ou bien une contamination par le système vasculaire ; cette dernière hypothèse est appuyée par nos observations sur la présence préférentielle de l'agent pathogène dans les vaisseaux du tégument interne. La contamination pourrait s'effectuer pendant la fécondation par l'intermédiaire des grains de pollen qui peuvent héberger la bactérie en surface (ELANGO \& LOZANO, 1980).

L'association insectes-bactérie dans le cas de la bactériose vasculaire, comme dans celui d'autres affections bactériennes (LEACH, 1964, MILleR \& SCHROTCH, 1972) joue un rôle important dans la dissémination. En ce qui concerne la survie, la détection de $X$. c. pv. manihotis dans le tractus intestinal de $Z$. variegatus au cœur de la saison sèche, période sans symptômes, suggère que les insectes pourraient aussi jouer un rôle dans la conservation. La dynamique des populations montre que le parasite est en situation défavorable en saison sèche où il se maintient à un niveau de population faible. Ce point du cycle biologique du parasite est important car il peut permettre d'orienter une lutte chimique préventive visant à atteindre l'inoculum épiphyte au début de sa phase de multiplication et, par conséquent, à limiter l'incidence de la maladie.

Les divers mécanismes de conservation que nous avons évoqués dans cet article permettent à la maladie de se perpétuer d'un cycle cultural à un autre et expliquent le caractère endémique de cette bactériose. De plus, la conservation de l'agent pathogène dans les tissus de l'hôte, ainsi que sa capacité de multiplication 
épiphyte, permettent d'interpréter le phénomène des explosions de la maladie dans des zones indemnes par introduction de boutures contaminées.

Reçu le 22 mai 1984. Accepté le 22 novembre 1984.

\section{REMERCIEMENTS}

Nous remercions MM. G. FABRES \& G. BANI pour la détermination des insectes cités dans cet article.

\section{RÉFÉRENCES BIBLIOGRAPHIQUES}

Bolhool B. B., Schmidt E. L., 1970. Immunofluorescence detection of Rhizobium japonicum in soils. Soil Sci., 110, 229-236.

Bolhool B. B., Schmidt E. L., 1973. A fluorescent antibody technique for determination of growth rates of bacteria in soil. Bull. Ecol. Res. Comm. (Stockhoim), 17, 336-338.

Buddenhagen I. W., 1965. The relation of plant-pathogenic bacteria to the soil, 269-284. In K. F. Baker, W. C. Snyder ; " Ecology of soil-borne plant pathogens ", Berkeley, Univ. Calif. Press, 571 p.

Daniel J. F., Boher B., 1978. Ecology of cassava bacterial blight : epiphytic survival of Xanthomonas manihotis on aerial parts of the cassava plant. Proc. 4th Int. Conf. Plant Pathol., Bacteria, Angers, France, 763-771.

Daniel J. F., Boher B., 1985. Epiphytic phase of Xanthomonas campestris pv. manihotis on aerial parts of cassava, Agronomie, 5 (2).

Daniel J. F., Boher B., Mabanza J., Makambila C., 1978. Cassava bacterial blight in the Congo : etiology, epidemiology and control. Rep. interdisc. workshop held at IITA. Ibadan, Nigeria, june 1978, 49-54.

Elango F., 1981. Epiphytic survival of Xanthomonas manihotis on common weeds in Colombia. Commun. $5^{e}$ Conf. Inter. bactéries phytopathogènes, Cali, Colombie.

Elango $\mathbf{F}$, Lozano C., 1980. Transmission of Xanthomonas manihotis in seed of cassava. Plant Dis., 64, 784-786.
Faure M., Dupouey P., Morelec M. J., 1977. Les techniques de l'immunofluorescence et les réactions immunoenzymatiques. Cours Institut Pasteur, Maloine S.A. Editeur, 566 p.

Hockenhull J., 1978. The adaptation of the fluorescent antibody technique for in situ detection of bacterial antigen in serial sections of plant tissue. Proc. 4th Int. Conf. Plant Pathol. Bacteria, Angers, France, 333-336.

Ikotun T., 1976. Survival of Xanthomonas manihotis, the cassava bacterial blight pathogen. Rep. of an interdisciplinary workshop held at IITA., Ibadan, Nigeria, 24-27.

Leach J. G., 1964. Observation on cucumber beetles as vector of cucurbit wilt. Phytopathology, 54, 605-607.

Leben C., 1965. Epiphytic microorganisms in relation to plant diseases. Annu. Rev. Phytopathol., 3, 209-230.

Miller T. D., Schroth M. N., 1972. Monitoring the epiphytic population of Erwinia amylovora on pear with selective medium. Phytopathology, 62, 1175-1182.

Persley G. J., 1978. Etudes sur l'épidémiologie et l'écologie de la bactériose du manioc. C. R. séminaire interdisc. IITA, lbadan, Nigéria, juin 1978, 5-9.

Purvis M. J., Collier D. C., Walls D., 1966. Laboratory techniques in botany. Butterworth and Co, Publ. 